BENTHAM OPEN
CrossMark
Content list available at: www.benthamopen.com/TOIDJ/
DOI: $10.2174 / 1874279301810010156,2018,10,156-159$

RESEARCH ARTICLE

\title{
Epidemiology of Urinary Tract Infection in Neonatal Intensive Care Unit of Mohammed VI University Hospital in Marrakech
}

\author{
Mariam Lagrine*, Fatiha Bennaoui, Nadia El Idrissi Slitine and Fadel Mrabih Rabou Maoulainine \\ Department of Pediatric, Neonatal Intensive Care Unit, Mohammed VI University Hospital, Marrakesh, Morocco
}

Received: June 29, 2018

Revised: October 8, 2018

Accepted: October 12, 2018

\section{Abstract: \\ Objective:}

The objective of our study is to estimate the extent of urinary infection among neonatal infectious diseases.

\section{Materials and Methods:}

This work concerns a retrospective study of 91 newborns with urinary tract infections, collected in the Mohammed VI neonatal resuscitation unit, Marrakesh.

\section{Results:}

The average age of our newborns at admission was 10.8 days. In 20 cases, there were signs of maternal urinary tract infections. The main reason for hospitalization was jaundice in $72.53 \%$ of cases. The symptomatology was dominated by fever in $16.48 \%$ of cases, followed by a refusal to suck in $5.5 \%$ of cases. Escherichia coli was the predominant germ in $61.5 \%$ of cases. A probabilistic antibiotherapy based on Ceftriaxone $3^{\text {rd }}$ Generation and aminoglycoside was instituted in all cases after it was adapted to the antibiogram data. Ultrasound revealed malformations in 21 cases.

\section{Conclusion:}

Neonatal urinary tract infection remains a common pathology. Its potential severity involving renal functional prognosis and the frequency of urinary tract malformations require early diagnosis and adequate management.

Keywords: Urinary tract infection, Newborn, Risk factor, Treatment, Epidemiology, Cytobacteriological examination.

\section{INTRODUCTION}

Urinary tract infection is a common reason for hospitalization in the neonatal period. This diagnosis is based on the clinic and the cytobacteriological examination of the urine. The bacteriological definition of the urinary tract infection is based on the bacterial concentration found in the urine, which is, with the identification of the bacterium, the major criterion for interpreting the result of the cultures. The objective of our study is to estimate the extent of urinary tract infection among neonatal infectious diseases. The clinical manifestations of urinary tract infection in the newborn infant are variable.

\section{MATERIALS AND METHODS}

We conducted a retrospective study in the neonatal resuscitation unit at the University Hospital in Marrakech, including all newborn infants presenting a urinary tract infection during January 2015 to December 2016.

\footnotetext{
* Address correspondence to this author at the Department of Pediatric, Neonatal Intensive Care Unit, Mohammed VI University Hospital, Marrakesh, Morocco, Tel: +212618181301; E-mail: lagrine.mariam@gmail.com
} 
The initial biological assessment showed C-reactive protein (CRP) $>20 \mathrm{mg} / \mathrm{L}$, White Blood Cells (WBC) counts $>25000 / \mathrm{ml}$, platelet counts $<100000 / \mathrm{ml}$ and bacterial culture yielded $>105 \mathrm{CFU} / \mathrm{ml}$ of collected urine. The collection of urine was done by the application of an adhesively sealed sterile collection bag, after disinfection of the skin of the genital region. The collection bag was changed systematically every 30 minutes. The use of a suprapubic aspirate generally is unnecessary.

Treatment will vary depending on the degree of elevation of CRP and its follow-up.

Bacteriological criteria for urinary tract infection have been bacteriuria greater than 100,000/ml and leukocyturia greater than $10,000 / \mathrm{ml}$. In case of uninterpretable results (several germs or absence of leucocyturia), the collection of urine is redone. The control of the effectiveness of the treatment was performed 48 hours after the start of treatment by a second cytobacteriological examination of the urine.

The radiological exploration was done in two stages:

- An ultrasound during the hospitalization;

- Retrograde urethrocystography in case of major anomalies in ultrasound;

- Patient follow-up consisted of summoning them for clinical evaluation, assessment of the observance of the prophylactic treatment, its readjustment depending on the weight, or even its stop.

\section{RESULTS}

The median age in our series is 10.8 days with extremes ranging from 2 days to 28 days. The male/female ratio was 2.03 .

The analysis of maternal anamnestic data found a history of maternal UTI during pregnancy in 8 cases, premature rupture of the membranes in 11 cases and fever in 1 case. The main reasons for hospitalization: Jaundice in 66 which include prolonged or worsening jaundice, fever in 20 cases and refusal to suckle in 10 cases.

The appearance of urine samples collected was clear in 68 cases, cloudy in 20 cases and in 3 cases, pyuria was found. Leukocyturia is greater than 10,000 leukocytes / $\mathrm{ml}$ in 78 cases with 75 cases having a positive culture and 3 cases with negative culture and it was less than 10,000 leukocytes / $\mathrm{ml}$ in 13 cases with positive culture. The most common causative organism is Escherichia coli $61.5 \%$ Klebsiella pneumoniae was found in 35.2\%.

The sensitivity of E.Coli to third generation cephalosporin reached $100 \%$ whereas for Klebsiella, it was $90 \%$. Concerning the aminoglycoside family; gentamicin and amikacin were tested on germs. Coli was sensitive to gentamicin in $100 \%$ of cases, and remained sensitive to amikacin.

Klebsiella was sensitive in $80 \%$ of cases to gentamicin, it was susceptible to amikacin in $100 \%$ of cases. CRP was high in $30.4 \%$ of cases. The combination of CBC and CRP results showed an inflammatory syndrome in $52.17 \%$ of cases. In addition, there was no evidence of alteration of renal function. In addition, there was no evidence of impaired renal function.

The ultrasonography of the urinary tract was pathological in 21 cases showing nephrocalcinosis or unilateral hydronephrosis in most of the cases, supplemented by cystography in 3 cases which had objectified a minimal bilateral ureterohydronephrosis case, megaureter with pyeloureteral junction syndrome in 1 case and pyelocalficial dilatation in 1 case.

Initial therapy included ceftriaxone ( $50 \mathrm{mg} / \mathrm{kg}$ daily) and aminoglycoside (gentamicin $3 \mathrm{mg} / \mathrm{kg}$ daily). The treatment with ceftriaxone prolonged in 19 cases at the same dose. The total duration of treatment was 10 days for $100 \%$. Gentamicin is only prescribed during the first 3 days of treatment. The recovery rate was good for all patients. This is evidenced by improved clinical status and sterilization of urine cultures performed at 48 hours of treatment in 10 patients $(43.47 \%)$. At the end of the treatment, the urine was sterile in $100 \%$ of cases.

\section{DISCUSSION}

The first description of newborn urinary tract infection dates from the beginning of the century, and the observations made are still valid. The confirmation of diagnosis is based on laboratory data. The clinical presentation varies from fever and signs of sepsis to minimal changes, or the infant may be without signs. Until 1960s, studies of urinary tract infection in the neonatal period were discrepant because they presented some criteria to define this infection and used 
divergent methodologies [1].

Currently, research indicates that urinary tract infection incidence is correlated to the presence of risk factors. The environment of the studied population, the intensive care unit, should also be taken into consideration. The population in our study had a urinary tract infection frequency of $1.8 \%$, a rate close to the low incidence limit of this disease in the neonatal period $[2,3]$.

In the newborn, the symptoms are misleading. Also, it is necessary to think about it and to make a cytobacteriological urine exam practice in front of general signs like fever, a break of the weight curve, persistent jaundice, a generally bad state, digestive disorders or a sepsis.

A neonatal urinary infection should be considered a priori acute pyelonephritis even in the absence of fever. The fever is only seen in 21 to $40 \%$ of cases; its absence does not exclude the diagnosis [1].

This finding may be due to the low risk in this study population, because in the absence of risk factors, the full-term infant rarely develops urinary tract infection. The population of this study ( 91 full-term infants) presented non-specific symptoms and positive urine culture collected by collection bag, which was considered to be the presumptive urinary tract infection diagnosis. Another consideration concerning the incidence of the urinary tract infection is its relationship to associated infectious pathologies; when newborn infants develop sepsis, for instance, there is a higher chance of developing urinary tract infection. Therefore, urinary tract infection should be considered in all infants who have signs of sepsis. Prematurity and male gender are classified as risk factors described in other studies [4, 1]. There is also a proportional relationship with the presence of renal and urinary tract malformations. Natural defenses in the urinary tract include antibacterial properties of urine and urinary tract mucosa, anti-adherence mechanisms, mechanical effects of urinary flow, and immune mechanisms. In the neonatal period, these mechanisms may fail, facilitating infection.

Urinary tract infection is defined as bacteriuria greater than 10,000 bacteria/ml, in an aseptic urine sample. The comparison of the results obtained by placing a collection bag and by suprapubic aspiration showed that suprapubic aspiration is more recommended for newborn [4 - 6].

This method, which is not yet common practice in our context, reduces diagnostic errors related to bacterial contamination and / or cell desquamation of periurethral origin. Its contraindications are disorders of haemostasis and dilation of digestive loops (exceptional risk of perforation of a digestive organ). The risks are minimal (1\% of transient macroscopic hematuria). Ultrasonographic guidance of the suprapubic aspiration improves its sensitivity from 60 to $96.4 \%$, which reduces the number of invasive procedures required and increases the volume of urine obtained. The presence of a high concentration greater than 10000 bacteria $/ \mathrm{ml}$ in pure culture in the urine collected is pathogenic. Bacteriologically, the predominance of $E$. coli is constant and varies from 58 to $80 \%$ depending on series. In our study, this germ is found in $61.5 \%$ of cases.

Most practitioners recommend a renal ultrasound scan after an episode of urinary tract infection in the neonatal period to rule out congenital abnormalities. Avoiding ureterocystography is usually delayed for 2 to 4 weeks after successful treatment to assess for vesicoureteral reflux $[5,7]$.

\section{CONCLUSION}

Urinary tract infection in the newborn remains common in the late neonatal period, especially in boys. The indication of the cytobacteriological examination must be very wide in late neonatal and postnatal infection in the face of any unexplained infectious symptomatology. We also insist on systematic research underlying uropathy and the need to start prophylactic treatment once the infection is suspected in order to prevent recurrence with complicated kidney problems.

\section{ETHICS APPROVAL AND CONSENT TO PARTICIPATE}

This work concerns a retrospective study of 91 newborns with urinary tract infections, collected in the Mohammed VI neonatal resuscitation unit, Marrakesh.

\section{HUMAN AND ANIMAL RIGHTS}

All research procedures followed were in accordance with the ethical standards of the committee "The Morrocan Code of Ethics" responsible for human experimentation (institutional and national). 


\section{CONSENT FOR PUBLICATION}

A written informed consent was obtained from the parents.

\section{CONFLICT OF INTEREST}

The authors declare no conflict of interest, financial or otherwise.

\section{ACKNOWLEDGEMENTS}

Declared none.

\section{REFERENCES}

[1] Kiernan SC, Pinckert TL, Keszler M. Ultrasound guidance of suprapubic bladder aspiration in neonates. J Pediatr 1993; $123(5)$ : 789-91. [http://dx.doi.org/10.1016/S0022-3476(05)80861-3] [PMID: 8229492]

[2] Klein JO, Long SS. Bacterial infections of the urinary tract, infectious diseases of the fetus and newborn. 4th. Philadelphia: Saunders 1995; pp. 925-34.

[3] Lohr JA, Downs SM, Dudley S, Donowitz LG. Hospital-acquired urinary tract infections in the pediatric patient: A prospective study. Pediatr Infect Dis J 1994; 13(1): 8-12.

[http://dx.doi.org/10.1097/00006454-199401000-00003] [PMID: 8170742]

[4] de Man P, Cläeson I, Johanson IM, Jodal U, Svanborg EC. Bacterial attachment as a predictor of renal abnormalities in boys with urinary tract infection. J Pediatr 1989; 115(6): 915-22. [http://dx.doi.org/10.1016/S0022-3476(89)80742-5] [PMID: 2685219]

[5] Ismaili K, Lolin K, Damry N, Alexander M, Lepage P, Hall M. Febrile urinary tract infections in 0- to 3-month-old infants: A prospective follow-up study. J Pediatr 2011; 158(1): 91-4.

[http://dx.doi.org/10.1016/j.jpeds.2010.06.053] [PMID: 20708748]

[6] Zorc JJ, Levine DA, Platt SL, et al. Clinical and demographic factors associated with urinary tract infection in young febrile infants. Pediatrics 2005; 116(3): 644-8.

[http://dx.doi.org/10.1542/peds.2004-1825] [PMID: 16140703]

[7] Naveh Y, Friedman A. Urinary tract infection presenting with jaundice. Pediatrics 1978; 62(4): 524-5.

[PMID: 362366]

(C) 2018 Lagrine et al.

This is an open access article distributed under the terms of the Creative Commons Attribution 4.0 International Public License (CC-BY 4.0), a copy of which is available at: https://creativecommons.org/licenses/by/4.0/legalcode. This license permits unrestricted use, distribution, and reproduction in any medium, provided the original author and source are credited. 